\title{
INFLUÊNCIA DE DIFERENTES TIPOS DE ESTACAS E SUBSTRATOS NA PROPAGAÇÃO ASSEXUADA DE HORTÊNSIA [Hydrangea macrophylla (Thunb.) Ser.]
}

\author{
Influence of different types of stem cuttings and substrates on the asexual reproduction of \\ hydrangea (Hydrangea macrophylla) (Thunb.) Ser.
}

\author{
Petterson Baptista da Luz ${ }^{1}$, Patrícia Duarte de Oliveira Paiva², Paulo Roberto Corrêa Landgraf ${ }^{3}$
}

\begin{abstract}
RESUMO
A hortênsia (Hydrangea macrophylla) é um arbusto semilenhoso de 1,0 a 2,5 m de altura, de folhagem e florescimento decorativos, muito utilizados como flor de vaso e planta para paisagismo. Conduziu-se este trabalho com o objetivo de estudar o enraizamento de estacas de três partes da planta: apical, mediana e basal; em três tipos de substratos: terra, areia e vermiculita, para a formação de mudas. As estacas foram retiradas das plantas matrizes e divididas em segmentos apical, mediano e basal, os quais foram colocados para enraizar em bandejas de isopor, nos substratos areia, terra e vermiculita, em estufa com nebulização. As estacas que apresentaram melhor qualidade de raízes foram as originadas da parte basal do ramo, sendo que o melhor enraizamento foi observado nas estacas colocadas em areia. As estacas obtidas de diferentes partes da planta não se diferenciaram quanto à porcentagem de enraizamento e quanto ao número de brotos formados. Já os substratos que proporcionaram o maior número de brotações foram a areia e a terra. Algumas estacas apresentaram formação de flores, ocorrendo com maior frequiência nas estacas apicais, sem efeito dos substratos. A areia foi o substrato que proporcionou os melhores resultados quanto à qualidade das raízes e porcentagem de enraizamento. O substrato terra foi superior apenas para o número de brotos por estaca, porém não diferenciou estatisticamente da areia. Mudas formadas de estaca da parte basal da planta se mostraram com qualidade superior.
\end{abstract}

Termos para indexação: Estacas, enraizamento, propagação, hortênsia.

\begin{abstract}
The Hydrangea (Hydrangea macrophylla) is a semi-ligneous shrub measuring $1.0 \mathrm{~m}$ to $2.5 \mathrm{~m}$ in height with decorative foliage and flat-topped or rounded clusters of white, pink, or blue flowers widely used as vase or pot flower as well as landscaping plant. The objective of this research work was to study the rooting of stem cuttings obtained from three different parts of the plant: apical, median and basal portions of the stems, in three different types of substrate: soil, sand and vermiculite, for production of new cuttings. The stems were cut from the mother plants and subdivided into apical, median and basal segments, which were then placed for rooting in styrofoam trays containing the three different substrates soil, sand, and vermiculite and arranged inside a growth chamber containing nebulization. The cuttings that presented the best root quality were the ones originated from the basal portion of the stem and sand was the substrate that provided best rooting. The cuttings obtained from the different parts of the plant did not differ as far as percent of rooting and number of sprouts formed are concerned. On the other hand, the substrates that provided highest number of sprouts were sand and soil. Some cuttings presented flower formation, with higher frequency on the cuttings from the apical segment, with no effect from substrate. Sand was the substrate that provided the best results concerning quality of roots and rooting percentage. The soil substrate was superior only for the number of sprouts per cutting although it was not statistically different from the substrate sand. Transplants originated from cuttings of the basal portion of the stem were qualitatively superior.
\end{abstract}

Index terms: Cuttings, reproduction, rooting.

(Recebido em 21 de junho de 2004 e aprovado em 27 de março de 2006)

\section{INTRODUÇÃO}

A hortênsia é um arbusto semilenhoso de 1,0-2,5 $\mathrm{m}$ de altura, de folhagem e florescimento decorativos. Possui folhas grandes, denteadas, brilhantes e coriáceas. Inflorescências compactas, com numerosas flores estéreis, de várias colorações. Tem origem na Ásia, principalmente China e Japão e é muito utilizada como flor de vaso e planta para paisagismo, desenvolvendo-se bem em regiões de clima ameno, a pleno sol ou meia-sombra. Existe uma grande variedade de híbridos, com flores de cores que vão do branco ao vermelho, em várias composições de formatos fazendo buquês diferentes (LORENZI \& SOUZA, 2001).

Na produção comercial, efetua-se a multiplicação mediante estacas de ponta de ramos podados no outonoinverno e cultivados em local protegido até enraizar. $\mathrm{O}$

\footnotetext{
${ }^{1}$ Doutorando em Produção e Tecnologia de Sementes, Universidade Estadual Paulista - Faculdade de Ciências Agrárias e Veterinárias - Campus de Jaboticabal - Via de Acesso Prof. Paulo Donato Castellane, s/n - 14884-900 - Jaboticabal, SP - petterbaptista@yahoo.com.br ${ }^{2}$ Engenheira Agrônoma, Dra., Professora Adjunto do Departamento de Agricultura/DAG -Universidade Federal de Lavras - Cx. P. 3037 - $37200-000$ Lavras, MG - pdolivei@ufla.br

${ }^{3}$ Engenheiro Agrônomo e Engenheiro Florestal, Dr., Professor da Universidade José Do Rosário vellano/UNIFENAS - Campus Universitário - $37130-000$ Alfenas, MG - paulo.landgraf@unifenas.br
} 
período de enraizamento vária de 20 a 40 dias, sendo feito sob nebulização intermitente, normalmente em bandejas ou em sacos de polietileno contendo geralmente como substrato areia (ABRIL CULTURAL, 1973). A cultura popular, no entanto, indica que as melhores estacas para produção de mudas são as obtidas da haste da inflorescência, retiradas logo abaixo desta. Entretanto, não se obteve comprovação científica para esta informação.

Em relação ao substrato mais adequado, não se encontrou registrada nenhuma informação para propagação de hortênsia. No processo de propagação por estaquia, diversas são as possibilidades de substratos para uso. Os mais comuns são areia, casca de arroz carbonizada, terra, húmus, vermiculita, dentre outros, e a mistura destes.

Avery \& Beyl (1991) afirmam que o uso de algumas tecnologias pode melhorar tanto a qualidade da muda quanto a porcentagem de enraizamento e qualidade das estacas enraizadas. Dentre estas, poder-se ia citar o uso de substratos mais adequados para proporcionarem maior enraizamento, melhor distribuição e conformação das raízes (HARTMANN et al., 1997; KLEIN et al., 2000; OFORI et al., 1996).

De acordo com Hoffmann et al. (1996), o substrato destina-se a sustentar as estacas durante o período de enraizamento, mantendo sua base em ambiente úmido, escuro e suficientemente aerado.

A utilização de areia como substrato é vantajosa, pois é de baixo custo, de fácil disponibilidade e apresenta características positivas quanto a drenagem, sendo seu uso adequado para estacas herbáceas e semilenhosas (FACHINELLO et al., 1994).

Gonçalves \& Minani (1994) sugerem para o enraizamento de estacas de calanchoe (Kalanchoe $x$ blossfeldiana) o uso de misturas de vermiculita + torta de filtro Oliver em várias proporções e a mistura de vermiculita + casca de arroz tostada (3:1).
Para o enraizamento de Primavera (Bougainvillea glabra var. gracilifora Heimerl) Landgraf et al. (2003) sugerem o uso de um substrato composto por húmus e terra $(3: 1)$.

Vazques e Mesquisa (2003) afirmam que o uso de vermiculita proporcionou uma melhor formação de raízes em ixora.

Com o presente trabalho, objetivou-se estudar o enraizamento de estacas de hortênsia obtidas de três partes da haste: apical, mediana e basal; em três diferentes substratos: terra, areia e vermiculita.

\section{MATERIAL E MÉTODOS}

Desenvolveu-se o experimento no Departamento de Agricultura da Universidade Federal de Lavras/UFLA, na primavera de 2003.

Para o estudo da formação de mudas de hortênsia utilizaram-se estacas de plantas matrizes do viveiro de plantas ornamentais. Os ramos foram seccionados em três segmentos de aproximadamente $9 \mathrm{~cm}$, os quais constituíram as estacas para enraizamento. Retiraram-se todas a folhas e colocaram-se as estacas nos substratos areia, vermiculita e solo (argiloso) para enraizamento. $\mathrm{O}$ solo foi classificado como classe textural argilosa, sendo os resultados das análises física e química apresentados nas Tabelas 1 e 2 .

O ensaio foi realizado em casa-de-vegetação com sistema de irrigação e $30 \%$ de sombreamento. Os substratos foram dispostos em bandejas de isopor com 72 células.

A avaliação foi realizada 40 dias após a instalação e os parâmetros analisados foram: qualidade das raízes, enraizamento, número de brotos e presença ou não de flor. À qualidade das raízes foram atribuídas notas de um a três que foram determinadas da seguinte maneira: as estacas que apresentavam maior volume de raízes e com um comprimento que chegasse ao orifício inferior da bandeja

TABELA 1 - Resultados da análise física do solo utilizado como substrato.

\begin{tabular}{cccc}
\hline $\begin{array}{c}\text { Areia } \\
\left(\text { (ag Kg }^{-1}\right)\end{array}$ & $\begin{array}{c}\text { Silte } \\
\left(\operatorname{dag~Kg}^{-1}\right)\end{array}$ & $\begin{array}{c}\text { Argila } \\
\left(\text { dag Kg }^{-1}\right)\end{array}$ & $\begin{array}{c}\text { Matéria orgânica } \\
\left(\operatorname{dag~Kg}^{-1}\right)\end{array}$ \\
\hline 21 & 23 & 56 & 3,3 \\
\hline
\end{tabular}

TABELA 2 - Resultados das análises químicas do solo utilizado como substrato.

\begin{tabular}{|c|c|c|c|c|c|c|c|c|c|c|c|c|c|c|c|c|}
\hline $\mathrm{pH}$ & b & $\mathrm{K}$ & $\mathrm{Na}$ & $\mathrm{Ca}^{2+}$ & $\mathrm{Mg}^{2+}$ & $\mathrm{Al}^{3+}$ & $\mathrm{H}+\mathrm{Al}$ & $\mathrm{Zn}$ & $\mathrm{Fe}$ & $\mathrm{Mn}$ & $\mathrm{Cu}$ & B & $\mathrm{S}$ & $\mathrm{V}$ & $(\mathrm{T})$ & $(\mathrm{t})$ \\
\hline$\left(\mathrm{H}_{2} \mathrm{O}\right)$ & \multicolumn{3}{|c|}{$\mathrm{mg} / \mathrm{dm}^{3}$} & \multicolumn{4}{|c|}{ Cmolc/dm ${ }^{3}$} & \multicolumn{6}{|c|}{$\mathrm{mg} / \mathrm{dm}^{3}$} & $\%$ & \multicolumn{2}{|c|}{$\mathrm{Cmolc} / \mathrm{dm}^{3}$} \\
\hline 6,9 & 8,5 & 70 & - & 6,0 & 0,9 & 0,0 & 0,9 & 4,2 & 33,0 & 23,4 & 1,5 & 0,5 & 37,2 & 88,7 & 8,0 & 7,1 \\
\hline
\end{tabular}

Ciênc. agrotec., Lavras, v. 31, n. 3, p. 699-703, maio/jun., 2007 
recebiam a nota 3 ; estacas com um volume mediano de raízes e com um comprimento que não chegasse ao orifício inferior da bandeja recebiam nota 2; estacas com poucas raízes e raízes menores que dois centímetros recebiam nota 1 .

O delineamento utilizado foi o inteiramente casualizado em esquema fatorial $3 \times 3$ (tipos de estacas e diferentes substratos) com 4 repetições e 4 estacas por repetição.

\section{RESULTADOS E DISCUSSÃO}

De acordo com a análise de variância, houve diferença significativa para os diferentes substratos e para as diferentes origens de estaca, em quase todos os parâmetros analisados. Não houve interação entre a posição da estaca e os substratos de cultivo para nenhum parâmetro.

As estacas que obtiveram melhor qualidade de raiz foram as originadas da parte basal da planta, e o substrato que proporcionou a melhor qualidade das raízes foi a areia (Tabela 3).

Os substratos inorgânicos, como a vermiculita, possuem pouca reserva de nutriente, o que pode ter causado esta resposta, segundo Loach (1988).

$\mathrm{O}$ desenvolvimento inferior das estacas mantidas em terra pode ser justificado pelo fato de esta apresentar alta densidade e pouca porosidade (KÄMPF, 2000), que não são características desejáveis para o enraizamento de estacas.

As estacas obtidas de diferentes partes da planta não se diferenciaram quanto à porcentagem de enraizamento, já os substratos que proporcionaram melhor porcentagem de enraizamento das estacas foram a terra e a areia, isoladamente (Tabela 4).

As estacas originadas de diferentes partes da planta não tiveram diferença entre si quanto ao número de brotos. Já os substratos que proporcionaram o maior número de brotações foram a areia e a terra (Tabela 5).

Quanto à porcentagem de estacas com inflorescência, a estaca que proporcionou uma maior porcentagem de formação de inflorescência foram às obtidas da parte apical, enquanto que os diferentes substratos não proporcionaram diferença para este parâmetro (Tabela 6).

Resultados contrários foram relatados por Gonçalves et al. (1991) que estudando o efeito de diferentes substratos no enraizamento de estacas apicais e não apicais de Rhipsalis elliptica G. Lindb., constataram que a vermiculita estava entre os melhores tratamentos. Em trabalho de enraizamento com Crisântemo [Chrysanthemum morjfolium (Ramat.) Tzvelev cv. Polaris], Takeyoshi et al. (1984) verificaram que a vermiculita proporcionou níveis satisfatórios de enraizamento, embora tenha exigido maior tempo para tal, dados concordantes com os obtidos por (MULLARD, 1954).

TABELA 3 - Qualidade de raízes de hortênsia em estacas originadas de diferentes partes da planta, em substratos diferentes.

\begin{tabular}{cccc}
\hline & Estacas & \multicolumn{2}{c}{ Substratos } \\
\hline Mediana & $1,23 \mathrm{~b}$ & Vermiculita & $1,04 \mathrm{c}$ \\
Apical & $1,42 \mathrm{~b}$ & Terra & $1,44 \mathrm{~b}$ \\
Basal & $1,81 \mathrm{a}$ & Areia & $1,98 \mathrm{a}$ \\
\hline $\mathrm{CV}$ & $18,63 \%$ & $\mathrm{CV}$ & $18,63 \%$ \\
\hline
\end{tabular}

As médias seguidas da mesma letra, na coluna não diferem entre si pelo teste de Scott Knott a 5\% de probabilidade.

TABELA 4 - Porcentagem de enraizamento de estacas de hortênsia em estacas originadas de diferentes partes da planta, em diferentes substratos.

\begin{tabular}{cccc}
\hline & Estacas & \multicolumn{2}{c}{ Substratos } \\
\hline Mediana & $77,08 \mathrm{a}$ & Vermiculita & $60,41 \mathrm{~b}$ \\
Apical & $83,33 \mathrm{a}$ & Terra & $93,75 \mathrm{a}$ \\
Basal & $89,58 \mathrm{a}$ & Areia & $95,83 \mathrm{a}$ \\
\hline CV & $9,96 \%$ & $\mathrm{CV}$ & $9,96 \%$ \\
\hline
\end{tabular}

As médias seguidas da mesma letra, na coluna não diferem entre si pelo teste de Scott-Knott a 5\% de probabilidade. 
TABELA 5 - Número de Brotos formados em estacas de hortênsias originadas de diferentes partes da planta, em diferentes substratos.

\begin{tabular}{cccc}
\hline & Estacas & \multicolumn{2}{c}{ Substratos } \\
\hline Apical & $2,27 \mathrm{a}$ & Vermiculita & $1,75 \mathrm{~b}$ \\
Mediana & $2,71 \mathrm{a}$ & Terra & $2,83 \mathrm{a}$ \\
Basal & $2,91 \mathrm{a}$ & Areia & $3,31 \mathrm{a}$ \\
\hline $\mathrm{CV}$ & $27,16 \%$ & $\mathrm{CV}$ & $27,16 \%$ \\
\hline
\end{tabular}

As médias seguidas da mesma letra na coluna não diferem entre si pelo teste de Scott Knott a 5\% de probabilidade.

TABELA 6 - Porcentagem de estacas com inflorescências de hortênsia originadas de diferentes partes da planta e enraizadas em diferentes substratos.

\begin{tabular}{cccc}
\hline & Estaca & & \multicolumn{2}{c}{ Substratos } \\
\hline Mediana & $2,08 \mathrm{~b}$ & Terra & $4,16 \mathrm{a}$ \\
Basal & $6,25 \mathrm{~b}$ & Vermiculita & $10,41 \mathrm{a}$ \\
Apical & $22,91 \mathrm{a}$ & Areia & $16,66 \mathrm{a}$ \\
\hline $\mathrm{CV}$ & $11,81 \%$ & $\mathrm{CV}$ & $11,81 \%$ \\
\hline
\end{tabular}

As médias seguidas da mesma letra na coluna não diferem entre si pelo teste de Scott Knott a 5\% de probabilidade.

Com relação à agregação do substrato às raízes (formação de torrão), a terra proporcionou melhor agregação do que os outros. Essa agregação é muito importante no transplantio, tendo em vista que, para um bom estabelecimento da muda, é essencial que esta não sofra danos no sistema radicular, o que pode ser evitado ou minimizado, mediante substratos que proporcionam boa agregação às raízes (torrão).

\section{CONCLUSÕES}

A areia foi o substrato que proporcionou os melhores resultados quanto à qualidade das raízes e porcentagem de enraizamento.

A estaca da parte basal da planta se mostrou superior em quase todos os parâmetros avaliados, vindo a perder para a estaca da porção apical da planta na porcentagem de estacas com inflorescência.

Contradizendo então a cultura popular, verificamos que as melhores estacas para produção de mudas de hortênsia são obtidas da parte basal da planta e o melhor substrato é a areia.

\section{REFERÊNCIAS BIBLIOGRÁFICAS}

ABRIL CULTURAL. Plantas e flores. São Paulo, 1973. $146 \mathrm{p}$.
AVERY, J. D.; BEYL, C. B. Propagation of peach cuttings using foam cubes. HortScience, Alexandria, v. 26, n. 9, p. 1152-1154, 1991.

FACHINELLO, J. C.; HOFFMANN, A.; NACHTIGAL, J. C.; KERSTEN, E.; FORTES, G. R. L. Propagação de plantas frutíferas de clima temperado. Pelotas: UFPel, 1994. $179 \mathrm{p}$.

GONÇALVES, A. L.; CATHARINO, E. L. M.; TOYOFUKU, R. A. Efeitos de diferentes substratos no enraizamento de estacas apicais e não apicais de Rhipsalis elliptica G.A. Lindberg, Cactaceae. In: CONGRESSO BRASILEIRO DE FLORICULTURA E PLANTAS ORNAMENTAIS, 8., 1991, Joinvile. Anais... Joinvile: UFSC, 1991. p. 68.

GONÇALVES, A. L.; MINAMI, K. Efeito de substrato artificial no enraizamento de estacas de calanchoe (Kalanchoe $x$ blossfeldiana cv. SINGAPUR, CRASSULACEAE). Scientia Agricola, Piracicaba, v. 51, n. 2, p. 240-244, 1994.

HARTMANN, H. T.; KESTER, D. E.; DAVIES, F. T.; GENEVE, R. L. Plant propagation: principles and practices. 6. ed. New Jersey: Prentice Hall International, 1997. $770 \mathrm{p}$. 
HOFFMANN, A.; CHALFUN, N. N. J.; ANTUNES, L. E. C.; RAMOS, J. D.; PASQUAL, M.; SILVA, C. R. de R. Fruticultura comercial: propagação de plantas frutíferas. Lavras: UFLA/FAEPE, 1996. 319 p.

KÄMPF, A. N. Produção comercial de plantas ornamentais. Guaíba: Agropecuária, 2000. 245 p.

KLEIN, J. D.; COHEN, S.; HEBBE, Y. Seasonal variation in rooting ability of myrtle (Myrtus communis L.) cutting. Scientia Horticulture, Amsterdam, v. 83, n. 1, p. 71-76, 2000 .

LANDGRAF, P. R. C.; ANDRADE, G. G.; SIMÕES, F. C.; LUZ, P. B.; PAIVA, P. D. de O. Propagação assexuada de estacas lenhosas de primavera (Bougainvillea Glabra Choisy var. Gracilifora Heimerl) com diferentes substratos e diferentes concentrações de hormônio. In: CONGRESSO BRASILEIRO DE FLORICULTURA E PLANTAS ORNAMENTAIS, 1.; CONGRESSO BRASILEIRO DE CULTURA DE TECIDOS DE PLANTAS, 14., 2003, Lavras, MG. Anais... Lavras: UFLA, 2003. p. 84.

LOACH, K. Controlling environmental conditious to improve adventitious rooting. In: DAVIS, T. D.; HAISSIG, B. E.; SANKHLA, N. Adventitious root formation in cuttings. Portland: Dioscorides, 1988. p. $248-273$.
LORENZI, H.; SOUZA, H. M. Plantas ornamentais no Brasil: arbustivas, herbáceas e trepadeiras. 3. ed. Nova Odessa: Plantarum, 2001. 1088 p.

MULLARD, S. R. Rooting cutting in vermiculite. Journal of the Royal Horticultural Society, London, v. 79, p. 367368, 1954.

OFORI, D. A.; NEWTON, A. C.; LEAKY, R. R. B.; GRACE, J. Vegetative propagation of Milicia excelsa by leaf ítem cuttings: effects of auxin concentration, leaf area and rooting médium. Forest Ecology and Management, Amsterdam, v. 84, n. 1/3, p. 39-48, 1996.

TAKEYOSHI, N. I.; ANRAKU, R. N.; MINAMI, K.; LIMA, A. M. L. P. Efeitos de diversos substratos no enraizamento de estacas de Chrysanthemum morifolium cv. Polaris. In: CONGRESSO BRASILEIRO DE FLORICULTURA E PLANTAS ORNAMENTAIS, 4., 1983, Rio de Janeiro, RJ. Anais... Brasília, DF: Embrapa, 1984. p. 137-142.

VAZQUES, G. H.; MESQUITA, K. A. C. Avaliação de diferentes substratos e doses de hormônio no enraizamento de estacas de ixora (Ixora coccínea L. inn "compacta"). In: CONGRESSO BRASILEIRO DE FLORICULTURA E PLANTAS ORNAMENTAIS, 1.; CONGRESSO BRASILEIRO DE CULTURA DETECIDOS DE PLANTAS, 14., 2003, Lavras, MG. Anais... Lavras: UFLA, 2003. p. 101. 